\title{
A Study of Quality Management of Entrepreneurship Practice Teaching Based on TQM
}

\author{
Zhenfeng Ge1, Ming Wang² \\ ${ }^{1}$ National Institute of Development Administration, Bangkok, Thailand \\ ${ }^{2}$ Ningbo College of Health Sciences, Ningbo, China \\ Email: dr.kevinge@gmail.com
}

How to cite this paper: Ge, Z.F. and Wang, M. (2017) A Study of Quality Management of Entrepreneurship Practice Teaching Based on TQM. Open Access Library Journal, 4: e3758.

https://doi.org/10.4236/oalib.1103758

Received: June 22, 2017

Accepted: July 16, 2017

Published: July 19, 2017

Copyright $\odot 2017$ by authors and Open Access Library Inc.

This work is licensed under the Creative

Commons Attribution International

License (CC BY 4.0).

http://creativecommons.org/licenses/by/4.0/

\section{Open Access}

\begin{abstract}
Guaranteed teaching quality is the key to specialty construction, and a teaching quality management system established in conformity with specialty characteristics is the foundation for talents cultivation [1]. This study, through field research at a Ningbo non-governmental undergraduate college (which sets up an entrepreneurship school and the first bachelor degree of entrepreneurship throughout China; referred to as "College D" in the following), conducts an analysis for the factors influencing teaching quality and focuses on the quality control over teaching practices.
\end{abstract}

\section{Subject Areas}

Education

\section{Keywords}

Entrepreneurship Education, Teaching Quality, Quality Management

\section{Introduction}

After two decades of development, colleges' entrepreneurship education in China has reached international advanced level in terms of curriculum types, teaching patterns, and Entrepreneurial team, particularly the higher number of students than that in America. However, it still lags far behind the Europe, America and some other countries in terms of study, practicing of teaching quality standards [1] [2]. To improve the quality of teaching, we must first find out the organizational form of entrepreneurship in colleges and universities in China. Only by clarifying the mode of entrepreneurship education can we better monitor 
and compare the quality of teaching. At present, there are no unified norms of the mode of entrepreneurship education in China's colleges and universities, focusing mode, magnet mode, radiation mode and other modes coexist, and the systematic quality supervision system is absent [3]. To make the level of teaching match the present scale of entrepreneurship education in a short term, we must break through the traditional concept of teaching quality management, and take a different perspective to rethink the approach to that management.

At present, the evaluation index of entrepreneurship education mainly includes the entrepreneurial teaching hardware environment, scientific research environment, practice base, campus culture, etc. [3]. This study found that many colleges and universities have ignored a core part of entrepreneurship education, which is the quality of practice teaching control, and no targeted evaluation indicators. In this study, a core concept of "user centered, user listening" is introduced for comprehensive teaching quality management. Clients in education industry mainly include students, parents, employing unit, the society, and some other interested parties [4]. Thus "students as the focus" should be the starting point and objective of the quality management for entrepreneurship education. And the introduction of TQM concept, technology to the existing quality control system, as well as the design of new appropriate quality management system for entrepreneurship education will help promote the education quality continually.

\section{Quality Management of Entrepreneurship Practical Teaching}

The complete entrepreneurial education system should be combined with the existing educational system of the school, including the theory and practice. And the weakening of the practice teaching is also the reason why the quality of China's entrepreneurship education is bad [5]. This study emphasizes the combination of theoretical teaching and practical teaching, and focuses on the evaluation of practical teaching quality. Based on learning about, analyzing the entrepreneurship education and quality management progress in college $\mathrm{D}$, the paper conducts research into the college's entrepreneurship education. The research is structured as in Figure 1.

\subsection{The Cultivation Model of Entrepreneurial Talents}

Through the study of College D's entrepreneurial teaching, a cyclic model of cultivation is developed, as shown Figure 2.

The model entails a combination of lateral, longitudinal chains. Longitudinally, cultivation of students proceeds from students entrance through graduates output, while laterally, it follows a "DMAIC" cycle. The emphases of teaching quality control lie in "prevention in advance" and "whole-process control". And the key part is the transition from result-oriented management to comprehensive quality management where both process control and engagement of all students are present. The structure mode is interpreted as Table 1. 


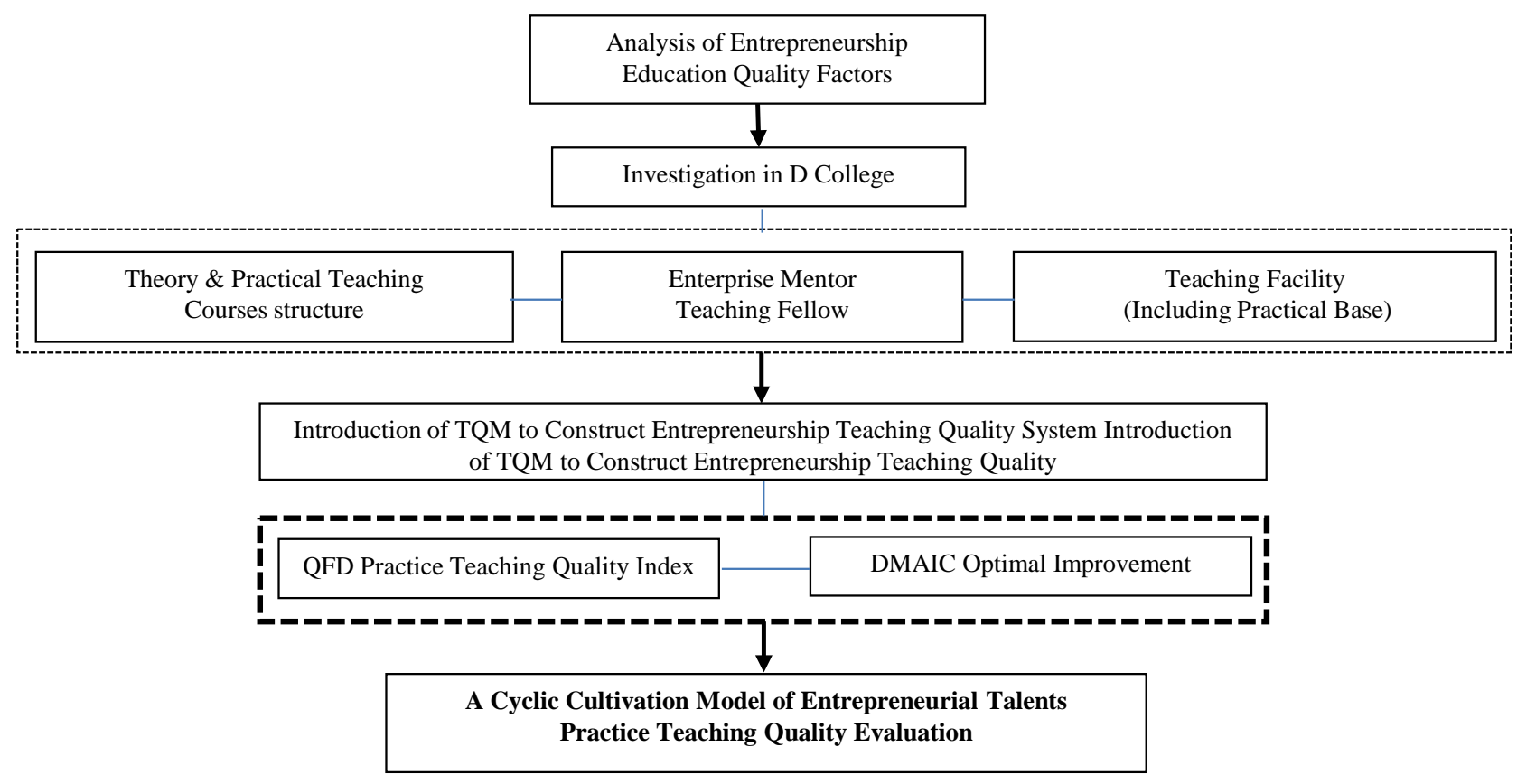

Figure 1. Research roadmap.

Table 1. The explanation of Figure 2.

\begin{tabular}{|c|c|}
\hline Longitudinal dimension & Horizontal dimension \\
\hline $\begin{array}{l}\text { Freshman input: } \\
\text { Selective mechanism: } 1 / 3 \text { students in D college apply } \\
\text { trinity of independent recruitment mode to pick up; } \\
\text { Noticeable: Including family background } \\
\text { investigation of students; }\end{array}$ & $\begin{array}{l}\text { Documents: } \\
\text { 1. On the basis of the original teaching documents, set up executive log, } \\
\text { record execution of practical teaching and theoretical teaching and execute } \\
\text { feedback information and live up to traceable teaching process; } \\
\text { 2. Establish adjustment mechanism of talent training program, and syste- } \\
\text { matic technical module course according to investment situation; }\end{array}$ \\
\hline $\begin{array}{l}\text { Talent cultivation and defect management: } \\
\text { 1. Professional import: set up professional background } \\
\text { import module in admission stage; } \\
\text { 2. Teaching: entrepreneurship module + technical } \\
\text { module + entrepreneurial practice; } \\
\text { 3. Defect management includes screening, selection, } \\
\text { connection and feedback. After finishing entrepreneurial } \\
\text { module and technical module, self-evaluation and school } \\
\text { evaluation are combined; }\end{array}$ & $\begin{array}{l}\text { Defect management: } \\
\text { 1. Evaluate according to entrepreneurial practical teaching quality } \\
\text { by school, college and teaching cooperator, student, teacher, } \\
\text { entrepreneurial mentor, and alumnus platform members } \\
\text { (Due to undergraduate teaching traits in entrepreneurial management, } \\
\text { entrepreneurial practical teaching is the priority among priorities); } \\
\text { 2. Pay attention to inputting course module management } \\
\text { (finished by entrepreneurial mentors); } \\
\text { 3. Establish the bi-directional evaluation mechanism; the college } \\
\text { will evaluate learning situation of students and students evaluate } \\
\text { the professional teaching in the college; } \\
\text { 4. Open the path for students to change a major; namely every } \\
\text { student has two chances to change a major after bi-directional evaluation; } \\
\text { 5. Continue maintaining entrepreneurial alumnus platform } \\
\text { and gather entrepreneurial teaching resources; }\end{array}$ \\
\hline
\end{tabular}

\subsection{The Design Ideas of Teaching Quality Management System}

The teaching quality management system for entrepreneurship education should have affinity with the cultivation objectives of entrepreneurial talents, and take the specifications, requirements of the Ministry of Education of PRC on discipline construction as a basis. That management system should be centered on the 


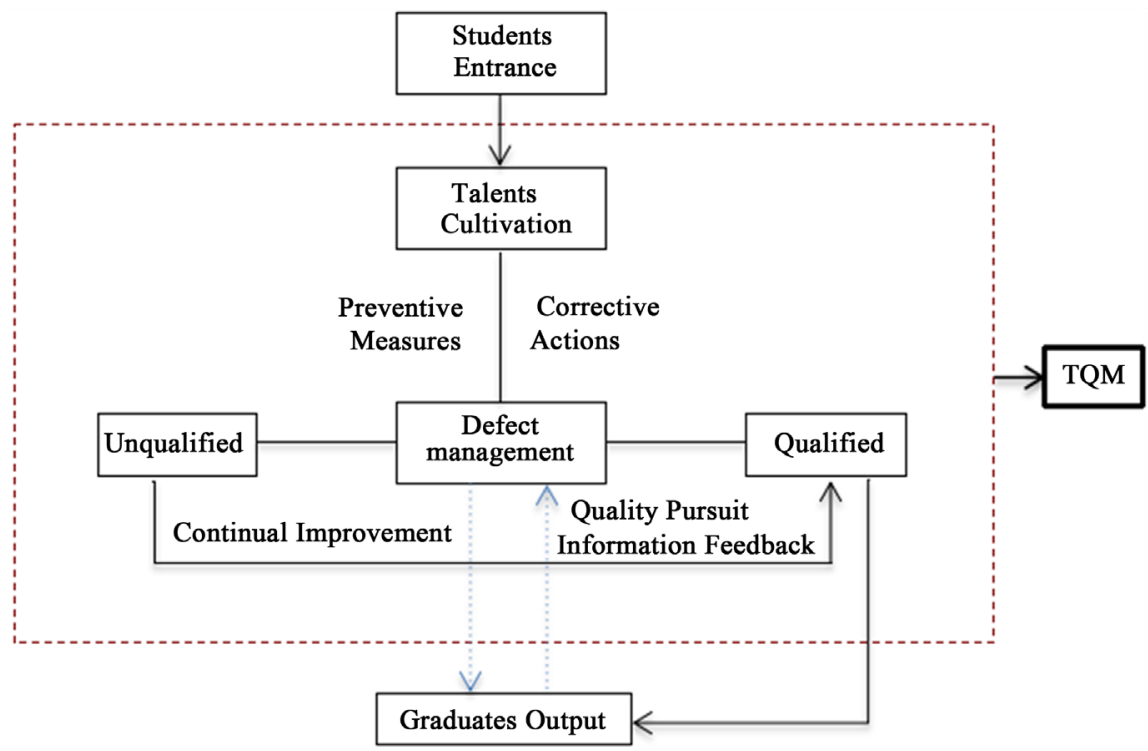

Figure 2. A cyclic cultivation model of entrepreneurial talents.

cultivation of enterprising quality and innovation ability [6]. Basically, four aspects should be involved in the design of such system: 1 . the balance between short-term and long-term objectives, and the blend of indexes measuring the past and the future; 2 . the combination of indexes connected with value appeal of colleges, students, the society and those mirroring internal processes, studies, growth, etc.; 3 . the matching of indexes associated with results to those relating to processes, which should be given particular attention; 4. the combination of objective quantitative indexes and subjective non-quantitative indexes, to which special attention must be paid [7].

The practice system of entrepreneurship education is based on cultivating students' innovative consciousness, entrepreneurial knowledge, innovative skills and entrepreneurial spirit. And entrepreneurial education practice carrier complex and practice system scattered, it will be difficult to support the quality of teaching quality [8]. Seeing from a disciplinary perspective, entrepreneurship is characterized, and also dominated by practice teaching. Therefore, in this paper the research focuses on the practice teaching.

\section{The Research at College D}

Different types of enterprise education in colleges and universities target varies. Even the same type of university, for its geographical, cultural, traditional, and student level differences, the teaching requirements and objectives will be different. These characteristics resulted in entrepreneurial education teaching evaluation cannot be stereotyped, but stressed the specific design [9]. It can be seen from College D's cultivation of entrepreneurial talents and entrepreneurship teaching that there is no quality evaluation criterion specifically set for entrepreneurship teaching, which is largely affiliated to business administration teaching. 


\subsection{An Overview of the Research}

The research is carried out in the form of questionnaires, semi-structured interviews, symposiums, partaking in practice teaching and classroom teaching, referring to relevant files, analyzing talents cultivation programs, studying the discipline construction plan, visiting the pioneering park, and interviewing entrepreneurial teams, etc.

The research finds that $28.1 \%$ of the students accepting entrepreneurship education are enrolled through the "trinity" of recruitment, having relatively lower Entrance Examination scores. And they choose to study entrepreneurship mainly for the opportunity to access undergraduate studies, with little attention paid to the discipline itself. In the light of the trend of College Entrance Examination, such students should increase in proportion year by year. And next year would see that proportion expanding to $40 \%$. Enrollment quality has become an important factor affecting the quality of entrepreneurship education.

\subsection{Research and Analysis}

The questionnaires that survey teaching satisfaction and primitive evaluation of the students adopt a 5-point Likert scale. The questionnaires are designed by full-time teachers, entrepreneurship tutors of college $D$, and entrusted to Ningbo Deeper information research Co., Ltd., a specialized research institution, for questionnaire distribution and analysis. A sample questionnaire is included in Appendix A. 150 questionnaires have been distributed, and 132 questionnaires collected, with 18 questionnaires failed to be retrieved.

Statistics of the sampled population show: the roughly equal ratio of male students and female students; $80 \%$ provincially local household registration; $66 \%$ enrollments via College Entrance Examination, and one third through the "trinity" of recruitment; 7 students switching from the discipline, 3 students switching to the discipline in the first year of studies, between which the ratio is over 2. Thus it can be seen that the discipline of entrepreneurship receives a low recognition, and is less attractive compared to traditional disciplines. Besides, there are deficiencies in the introductory educating of new students.

A survey of students' satisfaction for the discipline, fringe of the disciplinary knowledge, and rationality of curriculum design shows that $10.66 \%$ students are satisfied or quite unsatisfied, while $40 \%$ say they do not have much impression. This demonstrates that there is much room for the teaching quality to be improved. As talents cultivation program and curriculum design are the principal embodiment of teaching quality, if students are not attracted, the enrollment quality will be affected directly. And disciplinary development will lose momentum.

As to the practice curriculum and activities, $19.51 \%$ students say they are quite interested, $37.8 \%$ interested, and $2.44 \%$ quite uninterested, with $30.49 \%$ saying they do not have much impression. Results of the survey show that effective use of classroom knowledge has not gained importance in entrepreneurship practice, though practice is needed in perfecting the knowledge structure. As some 
students do not have much enthusiasm in attending practice curriculum and entrepreneurship practice, how to help them prize such activities and promote the participation in, enthusiasm for practice curriculum is of importance in quality management of entrepreneurship education.

About experiment equipment, library documents, and public services of the college, $13.41 \%$ students say they feel quite good, and $35.37 \%$ good. So the proportion of combined satisfaction is $48.78 \%$. However, $51.22 \%$ students say that the service quality needs to be improved. Among them, $4.88 \%$ students think the quality is poor. This shows the dissatisfaction for quality of the customeroriented services, which have affected feelings of a number of students. Apart from the hardware infrastructure, the college should also assign importance to its intangible infrastructure, the service functionality of which has effects on the overall teaching quality.

During the research, semi-structured interviews with 12 of the college's senior faculty and staff are conducted. And their shared attention is: strengthening of interpretation of national policies on entrepreneurship, orientation of the development of entrepreneurship education, and creation of more opportunities to enable students to be engaged in entrepreneurial practices. In teaching, the focuses should be the cultivation of students' leadership, innovation ability and global mind. In addition, breakthroughs are needed in current teaching mechanism, modularized curriculum and trans-disciplinary cultivation should be adopted (reinforced study of finance is specifically suggested), and as a mode of cultivation, inter-faculty exchange of students is recommended.

\section{Exploration of Establishing Quality Management System for Entrepreneurship Education}

The federal government's accreditation and recognition of the quality of accreditation of entrepreneurship education is a form of reevaluation; UK is the quality of the audit system to achieve the re-evaluation of the evaluation activities; The Dutch government also evaluates the meta-evaluation of the evaluation activities. These practices not only improve the evaluation objective and scientific, but also effectively improve the efficiency and effectiveness of the evaluation system [10]. Qin Jing-min [11] should be based on the content of entrepreneurial education system, design refinement of the quality control index system. From the full-time institutions, the main body participation, system incentives, after-school activities in four aspects, quality supervision and evaluation of two ways to learn about quality control of enterprise education in colleges and universities.

\subsection{Planning on Evaluation of Entrepreneurship Education Quality}

Through the research at College $\mathrm{D}$, with combination of the college orientation and the college's disciplinary development planning, this paper, after exploring the schooling norms, educational investment, infrastructure construction, teach- 
ing management, proposes 6 critical factors influencing entrepreneurship education quality management.

1) Schooling ideology: orientation of the discipline, schooling thoughts.

While highlighting the economic benefits and social development, determine the objectives over a length of time (including the education level, the focal points, orientation of the graduates, etc.) in the light of the college's orientation. For instance, College D's discipline is aimed for cultivation of entrepreneurs with enterprising spirits and entrepreneurial ability, in-service enterprising persons, and successors of family businesses.

2) Teaching staff: quality of the teaching staff, teacher cultivation.

Teaching staff refers to the full-time teachers, teaching management staff, and relevant positions include teaching, research and management positions. Currently, as a result of affiliation with economic administration specialty, there is a lack of full-time teachers with entrepreneurial experiences, and entrepreneurship teaching, research experience, which adds to the theoretical teaching in entrepreneurship education, and result in the slow pace in curriculum system construction, the failure of teaching management to suit entrepreneurship talents cultivation, etc. Hence, the construction of a high level specialized teaching team is the key to quality entrepreneurship education.

3) Teaching conditions: teaching expenditure, teaching infrastructure.

Teaching infrastructure is comprised of classrooms, laboratories, libraries, etc. And the essential guarantee for educational innovation is specialized laboratories designed specifically for entrepreneurship education. It is found in the research that College D's classrooms of creative design that is adapted to the characteristics of entrepreneurship education contribute significantly to the promotion of teaching efficiency.

4) External resources: angle funds, pioneer parks.

As a discipline, entrepreneurship attaches much importance to development of practical competence. And in practice teaching, probation bases along with angle funds are dispensable support resources. Hence, colleges should lay emphasis on improvement of their management of angle funds and other entrepreneurial resources, as well as allocating funds for entrepreneurial practices. These factors embody the core of entrepreneurship education quality.

5) Management ability: quality control, management team.

The teaching team and information construction level are elemental indexes for quality management. And control of process quality is often dependent on the management team's quality view and administrative ability.

6) Practice teaching: entrepreneurship tutors, project incubation.

Stress should be laid on the crucial difference between the practice teaching in entrepreneurship education and that in other discipline education. Given the strong practical nature of entrepreneurship education, the practice-oriented tutoring, the supervision of teaching quality, and the construction of tutor team that prizes the master-apprentice mode should have direct effect on the quality of entrepreneurship education. 


\subsection{Design of Quality System for Entrepreneurship Practice Teaching}

Practice teaching is the core part of entrepreneurial talents cultivation, and has effective control over the teaching quality. In this study, QFD technique is introduced into practice teaching quality control, and with students perceived as clients, quality management is investigated and designed for practice teaching.

\subsubsection{The Construction of Quality Evaluation System for Practice Teaching}

With VOC acquired, teaching indexes are established at two levels centering around the requirements on talents cultivation-knowledge, ability and quality; the evaluation elements are inferred from the second level indexes, as shown in Table 2.

Table 2. Evaluation of practice teaching quality.

\begin{tabular}{|c|c|c|c|c|c|c|c|}
\hline \multirow{2}{*}{$\begin{array}{l}\text { First level } \\
\text { index }\end{array}$} & \multirow{2}{*}{ Score } & \multirow{2}{*}{ Second level index } & \multirow{2}{*}{ Score } & \multirow{2}{*}{ Evaluation elements } & \multirow{2}{*}{ Score } & \multicolumn{2}{|c|}{ Assessment } \\
\hline & & & & & & Yes & No \\
\hline \multirow{3}{*}{ Students } & & Teamwork ability & & Perform work effectively in team & & & \\
\hline & & $\begin{array}{l}\text { Communicative and } \\
\text { coordinative competence }\end{array}$ & & $\begin{array}{l}\text { Communicate actively and coordinate } \\
\text { the parties involved }\end{array}$ & & & \\
\hline & & Entrepreneurship fundamentals & & Master essential entrepreneurial knowledge & & & \\
\hline \multirow{3}{*}{ Teachers } & & $\begin{array}{l}\text { Entrepreneurial } \\
\text { information competence }\end{array}$ & & $\begin{array}{l}\text { Strong competence to gain, understand, } \\
\text { handle and express information }\end{array}$ & & & \\
\hline & & $\begin{array}{l}\text { Guide entrepreneurship } \\
\text { project practice }\end{array}$ & & $\begin{array}{l}\text { Provide strong commercial, } \\
\text { technical support }\end{array}$ & & & \\
\hline & & Affinity with knowledge, skills & & $\begin{array}{l}\text { Provide commercial, technical } \\
\text { support at some degree }\end{array}$ & & & \\
\hline \multirow{4}{*}{$\begin{array}{l}\text { Instructional } \\
\text { design }\end{array}$} & & Objective design & & $\begin{array}{l}\text { Take fringe of knowledge and } \\
\text { practicality into full consideration }\end{array}$ & & & \\
\hline & & Capacity design & & $\begin{array}{l}\text { Cultivate students' resource integration } \\
\text { and knowledge application ability }\end{array}$ & & & \\
\hline & & Teaching means design & & Combine tutoring and process instruction & & & \\
\hline & & Teaching media & & $\begin{array}{l}\text { Comprising venture competitions, } \\
\text { cooperating parties, and pioneer parks }\end{array}$ & & & \\
\hline \multirow{3}{*}{$\begin{array}{l}\text { Teaching } \\
\text { feedback }\end{array}$} & & Knowledge construction & & $\begin{array}{l}\text { Students go through knowledge } \\
\text { construction process and have } \\
\text { mastery of fundamental knowledge }\end{array}$ & & & \\
\hline & & & & Teach with clarity and logicality & & & \\
\hline & & Collaborative teaching & & $\begin{array}{l}\text { Teacher-student interaction } \\
\text { have rationality and orderliness }\end{array}$ & & & \\
\hline $\begin{array}{l}\text { Composite } \\
\text { score }\end{array}$ & & Note & & & & & \\
\hline
\end{tabular}




\subsubsection{Application of QFD in Determination of Index Weight}

The heart of QFD's application is QH, which is a product planning matrix that depicts customer needs, quality characteristics, characteristic index target values, and product competitiveness evaluation. A teaching evaluation system is designed with QFD, as represented in Figure 3.

Elements of $\mathrm{QH}$ are listed as follows:

1) On the left "wall" of the house: students' requirements, i.e., a first level index; relative importance denotes the importance of the first level indexes, which is classified into 5 grades:

a) Quality requirements that have no effect on functionality;

b) Quality requirements that have no effect on major functionality;

c) Quality requirements of some importance that have effect on functionality;

d) Essential quality requirements that have effect on functionality;

e) Basic quality requirements that have effect on functionality.

2) On the ceiling of the house: teaching characteristics, i.e., the second level indexes;

3) In the house space: relationship matrix, i.e., relationship rij, which represents the relationship between first level indexes and second level indexes, adopting $1,3,5,7,9$, etc. as way of indicating degree of the relationship; in evaluating the quality of practice teaching, 1, 3, 5, 7, 9 are defined by teaching research specialists as follows:

1: Weak relationship;

3: Certain relationship;

5: Relatively close relationship;

7: Close relationship;

9: Extremely close relationship.

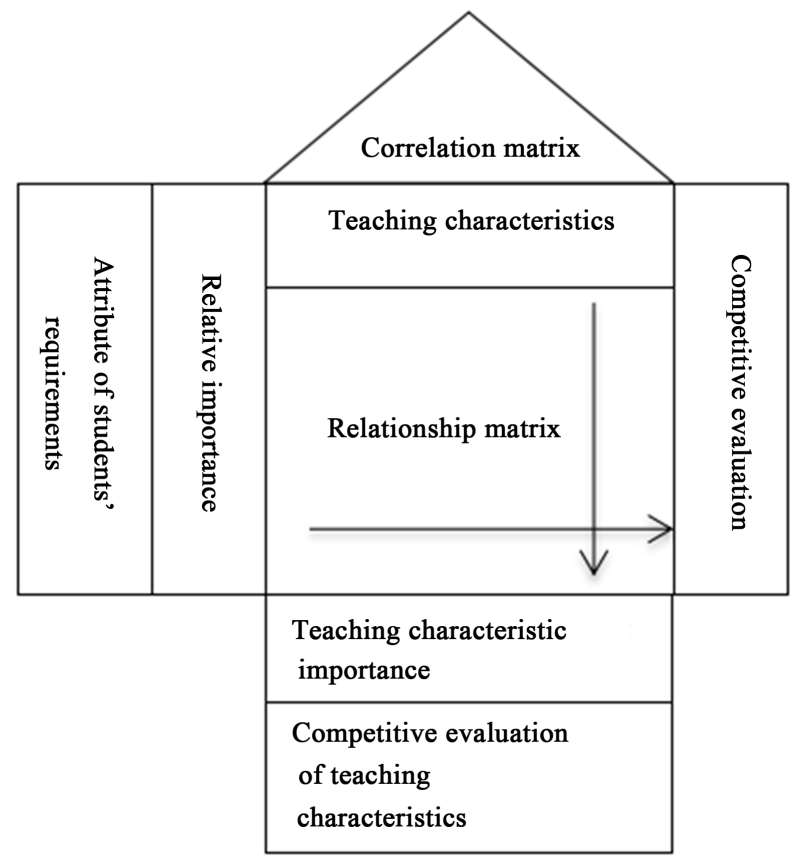

Figure 3. Quality house (QH) composition. 
4) On the "floor" of the house: Teaching characteristic importance and comparative evaluation of teaching characteristics;

5) On the "roof" of the house: Correlation matrix;

6) On the right "wall" of the house: comparative competition.

In evaluation of the quality of practice teaching, teaching characteristic importance $h_{j}$ is calculated according to the formula $h_{j}=\sum k_{i} r_{i j}(i=1,2,3, \ldots, m)$. Greater value of $h_{j}$ indicates higher importance of the quality, thus acting as the "key" to quality control.

And the weight of a second level index $j$ is calculated in accordance with the formula $100 \times \mathrm{h}_{\mathrm{j}} / \sum \mathrm{h}_{\mathrm{j}}$; the weight of a first level index is the sum of the weights of all the second level indexes below it, as shown in Table 3.

\subsubsection{Algorithm for Practice Teaching Quality Evaluation}

In scoring the quality of practice teaching, we need to score the evaluation elements pertaining to the second level indexes. For instance, as to the two evaluation elements pertaining to second level index collaborative teaching, if we do not factor in weight and assume the score of the index is 1, then scores of the evaluation elements are 0.5, 0.5 respectively. However, should an evaluation element does not satisfy relevant "standards", it scores 0 , otherwise, it scores 0.5 .

The pattern to calculate actual scores is as follows (taking second level index collaborative teaching for example):

1) Actual score of an evaluation element $=$ standard score $\times$ weight of relevant second level index, i.e., $0.5 \times 10.3=5.15$;

2) Calculate actual scores of the evaluation elements, then sum up those scores to obtain the score of the relevant second level index; likewise, calculate the scores of the rest second level indexes;

Table 3. Weights of indexes for evaluation of practice teaching quality.

\begin{tabular}{|c|c|c|c|c|c|c|c|c|c|c|c|c|c|}
\hline $\begin{array}{l}\text { Teaching } \\
\text { requirements }\end{array}$ & 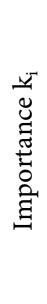 & 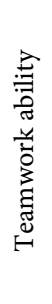 & 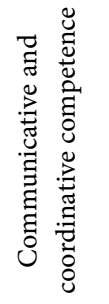 & 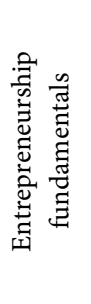 & 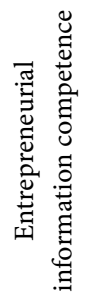 & 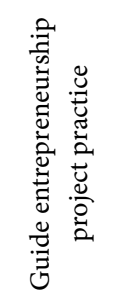 & 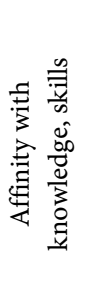 & 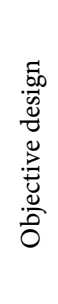 & 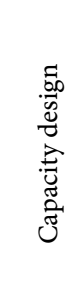 & 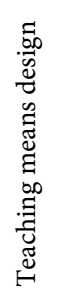 & 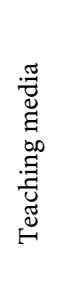 & 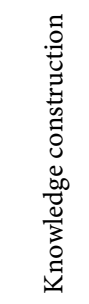 & 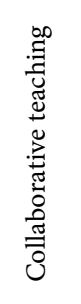 \\
\hline Students & 4 & 7 & 9 & 5 & & & & 3 & 3 & & & & 5 \\
\hline Teachers & 5 & & & & 5 & 9 & 7 & 5 & 5 & 7 & 5 & 1 & 5 \\
\hline Instructional design & 4 & 3 & 3 & 7 & 5 & 7 & 5 & 5 & 5 & 7 & 7 & 1 & \\
\hline Teaching feedback & 4 & 1 & 1 & 1 & 1 & 1 & 1 & 3 & 3 & & & 7 & 7 \\
\hline $\begin{array}{l}\text { Teaching characteri } \\
\text { importance } h_{j}\end{array}$ & & 44 & 52 & 52 & 49 & 77 & 59 & 69 & 69 & 63 & 53 & 37 & 72 \\
\hline Second level index we & & 6.3 & 7.5 & 7.7 & 7 & 11.1 & 8.5 & 9.9 & 9.9 & 9.1 & 7.6 & 5.3 & 10.3 \\
\hline \multirow{2}{*}{\multicolumn{2}{|c|}{ First level index weight }} & \multicolumn{3}{|c|}{21.5} & \multicolumn{3}{|c|}{26.6} & \multicolumn{4}{|c|}{28.9} & \multicolumn{2}{|c|}{15.6} \\
\hline & & \multicolumn{3}{|c|}{ Students } & \multicolumn{3}{|c|}{ Teachers } & \multicolumn{4}{|c|}{ Instructional design } & \multicolumn{2}{|c|}{ Teaching feedback } \\
\hline
\end{tabular}


3) finally, add together scores of all second level indexes to get the score of corresponding first level index.

The sum of the first level indexes' scores is the quality score of practice teaching. After being rounded, the scores rank as follows: 90 indicates excellence, 80 being good, 70 medium level, 60 acceptability, and 50 poor performance. Thus, intuitively practice teaching quality is measured. See Figure 4 for details of the algorithm for practice teaching quality evaluation.

\subsubsection{The Use of DMAIC for Improvement of Teaching Quality}

Each stage, following the evaluation of teaching quality, DMAIC methodology can be used to effect improvement cycles.

1) Define (D): Through statistical survey, initialize and conduct the program aimed for improvement;

At College D, we re-define the practice teaching of entrepreneurship, and allocate two weeks of practice to test of business proposals.

2) Measure (M): Measure up the maximum deviation factor, analyze VOC data to design TCQs, and determine the key quality characteristics;

Prior to the weeks of practice, classify students' requirements and expectations for practice teaching through symposiums and questionnaires.

3) Analyze (A): Render practical problems into quantitative indexes, and explore the underlying cause of defects using scientific statistical techniques;

We analyze the information acquired, and set goals for the weeks of practices.

4) Improve (I): By DOE, work out innovative solution to eradicate and prevent defects, as well as performing effectiveness test. This is the heart of DMAIC;

After setting the goal, we divide the subjects of practice teaching (i.e., the stu-

\begin{tabular}{|c|c|c|c|c|}
\hline \multicolumn{5}{|c|}{ Weights of Indexes for Evaluation of Practice Teaching Quality } \\
\hline \multicolumn{2}{|c|}{$\begin{array}{l}\text { Scores of evaluation } \\
\text { elements }\end{array}$} & \multicolumn{3}{|c|}{$\begin{array}{l}\text { Standard score } \times \text { weight of } \\
\text { corresponding second level index }\end{array}$} \\
\hline \multicolumn{2}{|c|}{$\begin{array}{l}\text { Scores of second level } \\
\text { indexes }\end{array}$} & \multicolumn{3}{|c|}{$\begin{array}{l}\text { Cumulative sum of scores of } \\
\text { correlative evaluation elements }\end{array}$} \\
\hline \multicolumn{2}{|c|}{$\begin{array}{l}\text { Scores of first level } \\
\text { indexes }\end{array}$} & \multicolumn{3}{|c|}{$\begin{array}{l}\text { Cumulative sum of scores of } \\
\text { correlative second level indexes }\end{array}$} \\
\hline \multicolumn{2}{|c|}{$\begin{array}{l}\text { Score of practice } \\
\text { teaching quality }\end{array}$} & \multicolumn{3}{|c|}{$\begin{array}{l}\text { Cumulative sum of scores of } \\
\text { relevant first level indexes }\end{array}$} \\
\hline \multicolumn{5}{|c|}{ Comprehensive score of practice teaching quality } \\
\hline 50 & 60 & 70 & 80 & 90 \\
\hline $\begin{array}{c}\text { poor } \\
\text { performance }\end{array}$ & acceptability & medium level & being good & excellence \\
\hline
\end{tabular}

Figure 4. Algorithm for practice teaching quality evaluation. 
dents) into two groups. For one group, the tutor defines the scope of innovative entrepreneurship, and conducts topic teaching in accordance with requirements of business proposals, while allowing 3 days at last for students to completion business proposals on themselves.

For the other group, the tutor provides the goal, business proposal template, study manual, but no teaching guidance. Eventually, one third of the students fail to complete their business proposals on time.

5) Control (C): It is the consolidation of gains, and the control of improvements as well.

The weeks of practice sees the experience gained in control of practice teaching, the perfection of management of practice teaching, and some improvement on quality of the teaching.

\section{Conclusions}

According to practical tests on teaching improvement, and reference, analysis of relevant literature, the following suggestions are made for construction of quality management system for college entrepreneurship education:

1) Be strict with the enrollment quality and attach importance to the "trinity" of recruitment.

2) Adopt the pattern of "foundational platform plus specialty module" in talents cultivation, and advocate inter-faculty exchange of students.

3) Assign importance to establishment of full-time teacher group, and the development of entrepreneurship teaching materials. Enrich teaching contents and teaching materials.

4) Introduce standardization systems such as ISO, etc. to regulate the management, service process. Allow the monitoring of teaching process, and the traceability of teaching outcome.

5) Referring to the evaluation mechanisms of AACSB, EQUIS, AMBA, rank, evaluate colleges' entrepreneurship education with the help of industry association or third parties, moreover, release the rankings for reference.

6) Strengthen the development of external resources, such as incubation base, venture capital, etc.

Evaluation of entrepreneurship education quality represents complex systems engineering. With restrictions on time, energy, knowledge capacity, etc., it's unlikely to build a commonly and perfect applicable index system for the evaluation within a short period. There is room for further study and exploration.

(1) Based on the deficiencies recognized in this study, contents of the questionnaires need perfection, and their scope expansion; the questionnaire sampling should have scientific and effectiveness.

(2) Principal factors influencing entrepreneurship education quality should be studied separately and more deeply. Attention to foreign studies should be strengthened for more references.

(3) Application of QFD for design, evaluation of teaching practices should continue to be studied; there should be attempts to apply it to the whole entre- 
preneurship education system, in order to facilitate the evaluation of entrepreneurship education quality in terms of scientificity, accuracy and efficiency.

\section{References}

[1] Lan, B. (1999). World Declaration on Higher Education. Journal of Yunnan RTV University, 4, 45-49.

[2] Liao, H. and Wang, X.-Y. (2015) A Probe into College Students' Enterprising Quality and Entrepreneurship Education. Art Taste, 12, 346.

[3] Wang, Y.-Q. (2016) Study on Management Model and Quality Evaluation of Enterprise Education in Colleges and Universities. Science \& Technology Information, $14,179-180$

[4] Sun, J. and Wang, M.-L. (2010) A Preliminary Study of Development Strategies of Vocational Education Group from the Perspective of Stakeholders. Vocational and Technical Education, 31, 47-50.

[5] Zhang, X.-G. and Zhao, J. (2013) From Entrepreneur Education to the Practice of Entrepreneurship: A Case Study of the Entrepreneur Education in Stanford University. Journal of Central South University of Forestry \& Technology (Social Sciences), 7, 163-166.

[6] Luo, F.-Y. (2015) The Inspiration of Britain's Youth Business International (YBI) for Youth Business in China. Training in China, 18, 79-80.

[7] Li, Y. and Wang, H.-Q. (2014) Design of BSC Based Index System for Quality Evaluation of College Entrepreneurship Education. Science Technology and Measurement, 2, 53-57.

[8] Wu, X.-C. and Lv, C.-Z. (2015) The Way out of the Dilemma on the Establishment of Practice System for Entrepreneurship Education in Universities: The Case of Zhejiang University. Fudan Education Forum, 13, 37-41.

[9] Ge, L. and Liu, Z.-Y. (2014) CIPP-Based Study on the Capability Evaluation Indicator System for Entrepreneurship Education at Chinese Universities and Colleges. Journal of Northeastern University (Social Science), 16, 377-382.

[10] Me Dowell, L. (1993) Enterprise Education and Part-Time Students. Assessment \& Evaluation in Higher Education, 18, 99-101.

[11] Qin, J.-M. (2010) A QFD-Based Study on College Enterprise Education Quality Evaluation. Doctoral Dissertation. 


\section{Appendix A: Questionnaire on Entrepreneurship Education Quality}

Dear students:

To promote overall entrepreneurship education of the college, this questionnaire is presented. It is answered anonymously and used for survey only. We guarantee the confidentiality of your answer. Thanks for cooperation! Please fill in the blanks or mark your choice with " $\checkmark$ ".

1. Gender

A) Male B) Female

2. Do you have a sense of belonging to the entrepreneurship education college?

A) Yes. It's strong B) Yes. It's at some level C) Yes D) No E) No. It's poor

3. Do you have a sense of recognition of the entrepreneurship discipline?

A) Yes. It's strong B) Yes. It's at some level C) Yes D) No E) No. It's poor

4. How do you evaluate the overall entrepreneurship education quality of the college?

A) Very good B) Good C) Ordinary D) Poor E) Very poor

5. What's your satisfaction of the courses?

A) Very good B) Good C) Ordinary D) Poor E) Very poor

6. How do you evaluate the teaching quality?

A) Very satisfied B) Satisfied C) Not bad D) Unsatisfied E) Very unsatisfied

7. How do you evaluate the college teaching?

A) Very satisfied B) Satisfied C) Not bad D) Unsatisfied E) Very unsatisfied

8. Are you interested in the practice courses?

A) Yes. Very interested B) Yes. Interested C) Maybe D) No E) No. Not interested at all.

9. Do you have a need to change the major?

A) Yes. I really have B) Yes, I have C) Maybe D) No E) That does not concern me

10. What is the role of college study in influencing and training your comprehensive quality?

A) Great B) Large C) Medium D) Little E) Very little

11. What will it be after your graduation?

A) Register for postgraduate examination B) Study abroad C) Entrepreneurship D) Find a job E) Wait for arrangement by my families

12. How much do you know about the entrepreneurship policies and guidance of the school?

A) Know much B) Know something C) Know little D) Know nothing E) That does not concern me

13. What's your satisfaction of the entrepreneurship atmosphere in the school?

A) Very satisfied B) Satisfied C) Not bad. D) Unsatisfied E) Very unsatisfied

14. How do you evaluate the service quality of the school?

A) Very good B) Good C) Ordinary D) Poor E) Very poor 
15. What's your satisfaction of the learning atmosphere in the school?

A) Very satisfied B) Satisfied C) Not bad D) Unsatisfied E) Very unsatisfied

16. Do you think the entrepreneurship college is more competitive than other colleges?

A) Yes. It's far more competitive B) Yes. It's more competitive C) I'm not impressed D) No. it's not competitive generally E) No. It's not competitive at all

Submit or recommend next manuscript to OALib Journal and we will provide best service for you:

- Publication frequency: Monthly

- 9 subject areas of science, technology and medicine

- Fair and rigorous peer-review system

- Fast publication process

- Article promotion in various social networking sites (LinkedIn, Facebook, Twitter, etc.)

- Maximum dissemination of your research work

Submit Your Paper Online: Click Here to Submit

Or Contact service@oalib.com 